\title{
Screening and Evaluation of the Biodegradation of Glass Fiber by Bacillus Mucilaginosus
}

\author{
Lingxia $\mathrm{Xu}^{1,2}$, Kunlun $\mathrm{Li}^{3}$, Yan Liang ${ }^{1,4}$, Lin Zhao ${ }^{1,2, a, ~ * ~}$ \\ ${ }^{1}$ Qilu University of Technology (Shandong Academy of Sciences), Shandong Jinan 250353, China; \\ ${ }^{2}$ Shandong Provincial Key Laboratory of Microbial Engineering, Shandong Jinan 250353, China; \\ 3 Jinan Hangchen Biological Technology Co., Ltd. Jinan, 250353, China; \\ ${ }^{4}$ College of Food Science and Engineering, Qilu University of Technology (Shandong Academy of \\ Sciences), Jinan, Shandong 250353, China. \\ *, a Zhaolin@163.com
}

Keywords: Bacillus mucilaginous; glass fiber; microorganism degradation; potassium degradation ability.

\begin{abstract}
This paper, 9 strains of bacillus producing capsule were isolated from soil by potassium shale medium. Glass fibers with similar structure of the ore were used as potassium sources. And the potassium degradation ability of the selected strain was analyzed by the weight loss method. The bacillus with the obvious degradation effect was screened out and named as X SC-6. According to the analysis of physiological characteristics and $16 \mathrm{~S}$ drank sequence, the fungus was confirmed to be Bacillus mucilaginous. To optimize the degradation condition, the fermentation medium also discussed. The results showed that the potassium degradation effect of potassium shale medium was better than the other. Attractively, the $\mathrm{K}^{+}$content in the supernatant was increased by $12.97 \%$ and the degradation rate reached $2.44 \%$. In addition, scanning electronic microscope was used to measure the microstructure of the glass fiber before and after degradation. The results indicated that the bacteria had good ability to decompose the potassium. This work provides supporting theories for the degradation of solid wastes (such as glass fiber) by microorganism.
\end{abstract}

\section{Introduction}

During the producing process of glass fiber, the existence of discarded glass fiber scraps is unavoidable. The waste of glass fiber occupied $15 \%$ of the entire production process [1]. Due to its unique product performance and composition, glass fiber cannot be normally degraded in the normal environment. Traditional handling method was heated to ultra-high temperatures for recycling use or applied as simple asbestos products. All of these methods resulted in exhaust emission and caused extremely high cost [2-3]. In view of environmental protection and cost control. High-temperature recycling method had become unpopular. Simple asbestos products are mostly used for temporary convertible and decorative application, Due to the addition of other chemical components, they existed the disadvantages of carcinogenicity and how safety factor. Therefore, this method had been banned internationally. It is particularly tempting to find a new way to dispose of waste glass fibers.

As we know, Bacillus mucilaginosus is regard as silicate bacteria or potassium bacteria, which is different from the common Bacillus bacteria. It is a special kind of soil Bacillus, which deserved the ability to decompose and transform silicate minerals [4]. Lots of literatures have reported that Bacillus mucilaginosus was applied in the degradation of $\mathrm{K}^{+}$. For glass fiber, it displayed certain similarity in composition with ore, such as $\mathrm{SiO}_{2}, \mathrm{Al} 2 \mathrm{O} 3$, Cano, $\mathrm{KO} 2$ and so on [5]. Thus, it is possible to degrade waste glass fibers by Bacillus mucilaginosus. All of the results provide a theoretical basis for seeking a new environment-friendly degradation method. 


\section{Materials and Methods}

\subsection{Sample.}

In this paper, soil samples and glass fibers were respectively taken from Changqing District and Taishan Glass Fiber Co., Ltd in Shandong Province.

\subsection{Medium.}

\begin{tabular}{|c|c|c|}
\hline $\operatorname{MEdium}(\mathrm{g} / \mathrm{L})$ & Component & $\mathrm{pH}$ \\
\hline Potassium porder medium & $\begin{array}{l}\text { Sucrose }(5 \mathrm{~g}), \mathrm{MgSO}_{4} .7 \mathrm{H} . \mathrm{O}(05 \mathrm{~g}), \mathrm{FeCl}_{3}(0.005 \mathrm{~g}), \\
\mathrm{CaCO} ;(0.1 \mathrm{~g}), \mathrm{NaH}_{4} \mathrm{PO}_{4}(1 \mathrm{~g}), \text { PotashShale Porder } \\
(1 \mathrm{~g}), \mathrm{Agar}(17 \mathrm{~g})\end{array}$ & 7.2 . \\
\hline Slope and preservationmedim & $\begin{array}{l}\text { Sucrose }(5 \mathrm{~g}) \text {, yeast }(05 \mathrm{~g}), \mathrm{NaH}_{2} \mathrm{PO}_{4}(1.5 \mathrm{~g}), \mathrm{NaCl}(1 \mathrm{~g}) \text {, } \\
\mathrm{MgSO}_{4}(0.5 \mathrm{~g}), \mathrm{FeCl}_{3}(0.005 \mathrm{~g}), \mathrm{Agar}(17 \mathrm{~g})\end{array}$ & 7.0 \\
\hline Potassium medium 1 & $\begin{array}{l}\text { Molasses }(15 \mathrm{~g}) \text {, Soybean meal }(7 \mathrm{~g}), \mathrm{NaH}_{3} \mathrm{PO}_{4}(1.5 \mathrm{~g}) \\
\mathrm{NaCl}(1 \mathrm{~g}), \mathrm{MgSO}_{4}(05 \mathrm{~g}), \mathrm{FeCl}_{3}(0.005 \mathrm{~g})\end{array}$ & 7.0 \\
\hline Potassium medium 2 & $\begin{array}{l}\text { sucrose }(5 \mathrm{~g}), \text { yeast }(05 \mathrm{~g}), \mathrm{NaH}_{3} \mathrm{PO}_{4}(1.5 \mathrm{~g}), \mathrm{NaCl}(\mathrm{g}) \text {, } \\
\mathrm{MgSO}_{4}(0.5 \mathrm{~g}), \mathrm{FeCl}_{3}(0.005 \mathrm{~g}), \mathrm{Agar}(17 \mathrm{~g})\end{array}$ & 7.0 \\
\hline
\end{tabular}

\subsection{Instrument.}

Ultraviolet Clean Bench, optical microscope, refrigerator, direct-reading $\mathrm{pH}$ meter, Autoclave, electronic balance, Muffle furnace, high speed centrifuge, constant temperature incubator, PCR amplification.

\section{Experiment}

\subsection{Glass Fiber Pretreatment.}

The glass fiber was baked in a muffle furnace at $550{ }^{\circ} \mathrm{C}$ for 4 hours to remove the impregnating compound that stick on the glass fiber surface. Then cooled to room temperature and pulverized into powder.

\subsection{Screening of Strains.}

Preliminary screening.Ore $(5 \mathrm{~g})$ was dissolved in $45 \mathrm{~mL}$ of normal saline, and the solution was shaking thoroughly with a shaker for $40 \mathrm{~min}$ to fully homogenize. Then the sample was kept at $50^{\circ} \mathrm{C}$ water bath for 15-20 min, and attenuate according to 10-2, 10-3, 10-4, 10-5 and 10-6, respectively. The bacterial suspension $(100 \mu \mathrm{L})$ was coated on a potassium shale mineral flour medium plate, cultured with a constant temperature incubator at $30^{\circ} \mathrm{C}$ for 2 to 3 days. The single colony having a large single transparent colony characteristic of Bacillus mucilaginosus was picked and numbered. The preliminary screening strains were numbered as X SC1-9 [6-8].

Rescreen.After baking in a muffle furnace at $550{ }^{\circ} \mathrm{C}$ for 4 hours, the glass fiber was ground into powder. Adding with the ratio of $60 \mathrm{~g} / \mathrm{L}$, primary strains were cultured in shake flasks and cultured in potassium shale ore powder medium with the volume of $50 \mathrm{~mL} / 250 \mathrm{~mL}$. Two rings of primary screening strains were selected in the inoculation loop to enter the culture medium and cultured on a shaker at $30^{\circ} \mathrm{C}$ at $150 \mathrm{r} / \mathrm{min}$ [9]. Three parallel groups were set in each group. After 72 hours of cultivation, they were taken out and centrifuged at $10000 \mathrm{r} / \mathrm{min}$ for $10 \mathrm{~min}$. The supernatant was removed. The precipitate was dried in muffle furnace at $550{ }^{\circ} \mathrm{C}$ for $4 \mathrm{~h}$ to remove ash. After drying, the mass difference was weighed. Comparing with the spore morphology of the primary screening strains, the strain with the best differential weight was selected as the starting strain.

Morphological species. The colony morphology of the strain and the individual morphology were observed under the microscope.

Molecular biology identification of bacterial species.According to the recordation of Common Bacterial System Identification Manual, Bacillus species were identified by morphological, physiological, biochemical characteristics and 16S rDNA sequence analysis [10].

\subsection{Determination of Potassium Release Capacity.}

Flame photometric determination of $\mathrm{K}+$ concentration in supernatant solution. The identified strains were rejuvenated for 2 or 3 times and then stored at $4{ }^{\circ} \mathrm{C}$. The superfine pulverized glass fiber was added to the potassium-dissolving medium 1 and the potassium-removing medium 2 according to the ratio of $60 \mathrm{~g} / \mathrm{L}$. The two mediums were sterilized at $121^{\circ} \mathrm{Cand} 115^{\circ} \mathrm{C}$ for $30 \mathrm{mins}$. 
Two or three loops of well-activated bacteria were inoculated into two mediums, and cultured at $30^{\circ} \mathrm{C}, 150 \mathrm{r} / \mathrm{min}$ for 3 days. Each group had 3 replicates. Potassium shale ore powder medium has a high viscosity after liquid culture. In order to reduce the viscosity, it was sealed and heated at $90^{\circ} \mathrm{C}$. The supernatants were obtained after centrifuged at 10,000 r/min for $20 \mathrm{~min}$ for each medium. Flame photometer was used to measure $\mathrm{K}$ content with $4 \mathrm{~mL}$ supernatants.

The blank group was set without the Bacillus mucilaginosus, and the others were consistent with the above-mentioned methods.

SEM analysis. The pre-degraded glass fibers and the degraded glass fibers were measured by scanning electron microscopy (SEM) to verify whether they played a role in degradation by comparing the smoothness of the surface of the glass fibers.

\section{Results and Discussion}

\subsection{Screening of Strains.}

In the processing of growth and metabolism, Bacillus mucilaginosus releases extracellular organic acids, such as acetic acid and lactic acid. These acids can destroy the crystal lattice of silicate minerals and release potassium, silicon and other elements [11]. Glass fiber contains a large number of mineral substance. Its main components are silica, alumina, calcium oxide, potassium dioxide. According to the degradation rate of glass fiber in Table 1, it can be found that Bacillus mucilaginosus has played an important role in the degradation of glass. The overall degradation rate of the selected strain X SC- 6 reached 3\%, whereas X SC-4 and X SC-7 are less than 1\% and the other strains have reached more than $1 \%$. Therefore, X SC-6 strain with the highest degradation rate was selected as the starting strain.

Table 1. Degradation ratio of different strains

\begin{tabular}{cccccccccc}
\hline Strain/X SC & 1 & 2 & 3 & 4 & 5 & 6 & 7 & 8 & 9 \\
\hline Time/3d & 3 & 3 & 3 & 3 & 3 & 3 & 3 & 3 & 3 \\
Number of Bacteria/( $\times 108 \mathrm{cfu} / \mathrm{mL})$ & 1 & 1.1 & 1.1 & 0.9 & 1.2 & 1 & 1.1 & 1 & 1 \\
Difference/g & 0.07 & 0.04 & 0.05 & 0.01 & 0.08 & 0.09 & 0.02 & 0.04 & 0.06 \\
\hline
\end{tabular}

4.2 Morphological Characteristics of Strains.

As shown in Figure 1. A, on a fresh medium incubated at $30^{\circ} \mathrm{C}$ for 36 hours, the colonies were smooth and transparent. Meanwhile, the edges were neat, the middle uplifted, and the threads were drawn into a line and a clear glass color. As shown in Figure 1.b, a single colony, stained by ammonium oxalate crystal violet, displayed the individual morphology of the bacterium Bacillus spp under oil microscopy. Bacillus mucilaginosus as a special gram-negative Bacillus mucilaginosus exhibited rod-like or fusiform organisms with 3-5 $\mu \mathrm{m}$ long and 0.8-1.5 $\mu \mathrm{m}$ wide. It contains one to several fat particles in cells. In addition, the surface of bacteria showed hypertrophic decidua and several bacteria was easily to form bacteria group [12].
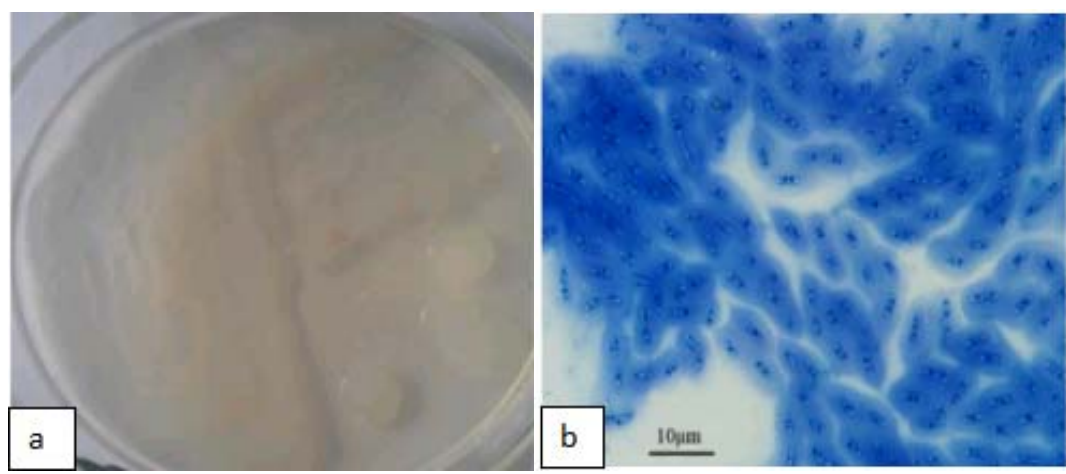

Figure 1. Colony morphology and individual morphology of Bacillus mucilaginosus

\subsection{Molecular Biology.}

The 16S rDNA sequence of Bacillus mucilaginosus were obtained from sequencing company and were BLAST by DNAStar. It was identified as a genus. The phylogenetic tree of this strain was 
established. From the phylogenetic tree in Figure 2, this strain is the same as Bacillus mucilaginosus. The interspecific similarity with 2 Bacillus mucilaginosus was $100 \%$, and the homology was greater than $99 \%$ with Bacillus mucilaginosus strain AHZ1 and Bacillus mucilaginosus AC2. The strain can be initially identified as Bacillus mucilaginosus and named as X SC-6.

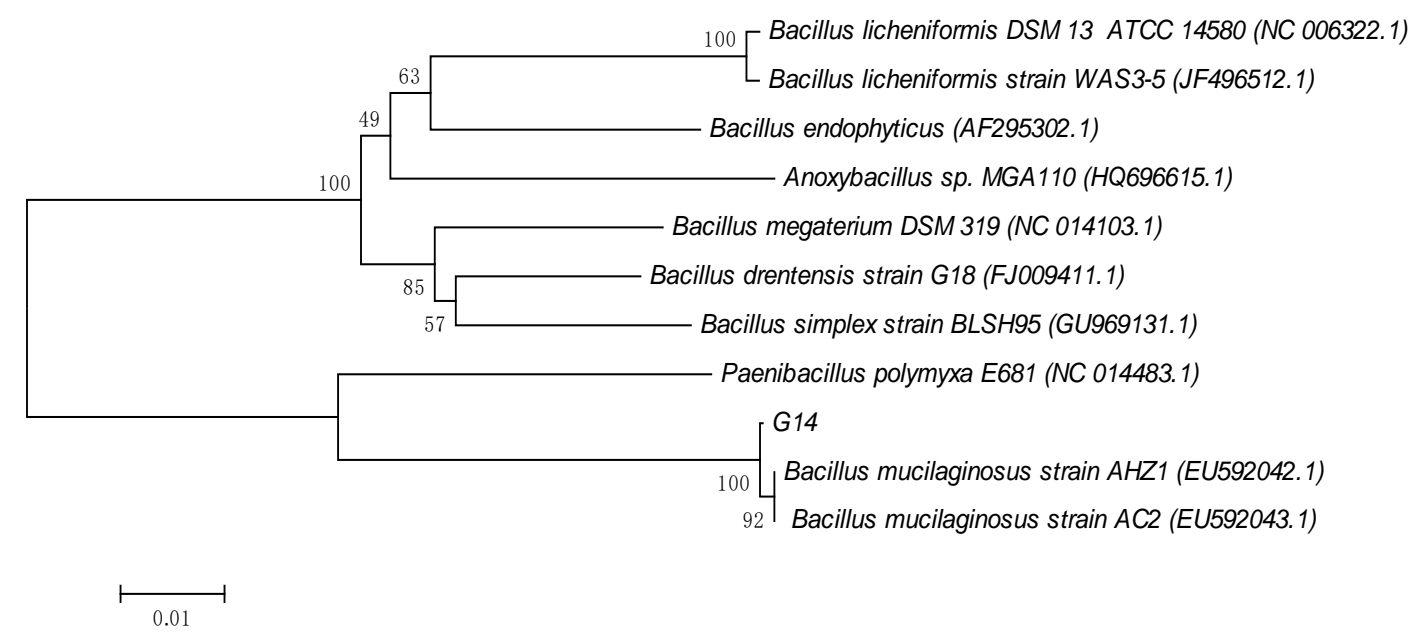

Figure 2. Phylogenetic Tree of 16S rDNA Sequences of Bacillus mucilaginosus X SC-6 and Related Strains

\subsection{Potassium Dissolving Ability Analysis}

Determination of $\mathrm{K}+$ concentration.From Figure 3, the linearity of the $\mathrm{K}+$ standard curve $(y=4.9317 x+0.24 R 2=0.9997)$ indicated that the test conditions were good and stable. By measuring the $\mathrm{K}+$ concentration of the two potassium-solubilizing medium supernatants, the blanks also contain trace amounts of potassium (displayed in Figure 4) [13]. The blank potassium ion contents of the two media are different. It may be due to chemical groups inside the reaction, or the medium itself contains a certain amount of potassium. Both of the two Medias showed an increasing trend of potassium ion concentration. And the potassium concentration in the supernatant of the potassium decontamination medium 1 was increased by an average of $0.887 \mathrm{mg} / \mathrm{mL}$. The $\mathrm{K}+$ concentration in the supernatant of the potassium solution media 2 was increased by an average of $0.836 \mathrm{mg} / \mathrm{mL}$.

\section{$\mathrm{K}^{+}$concentration standard curve}

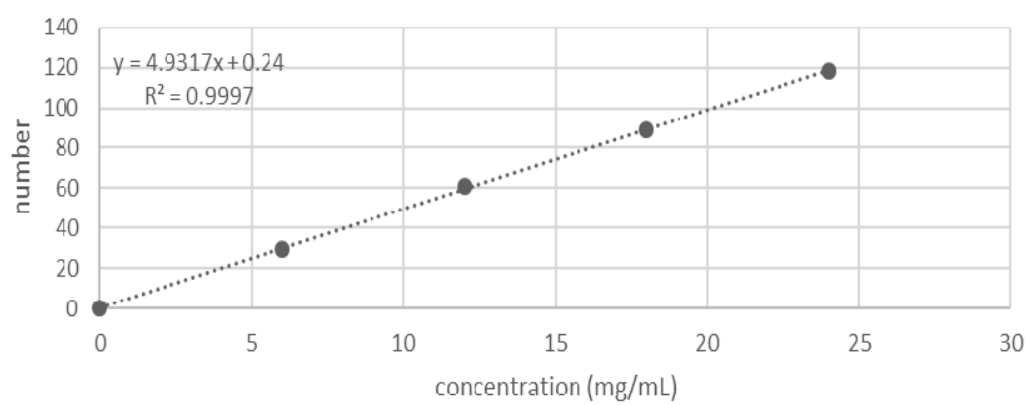

Figure 3. $\mathrm{K}+$ concentration standard curve
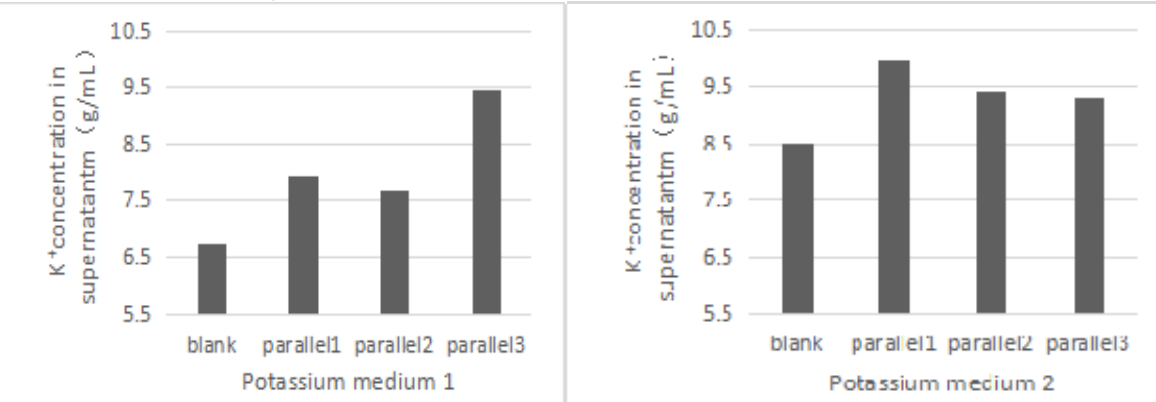

Figure 4. K+ Concentration in Supernatant from Two Culture Media

Comparison of two media degradation.Based on the above mentioned, we can conclude that the average increase rate of medium 1 in the solution of potassium is $12.97 \%$, and the average increase 
rate of medium 2 is $10.86 \%$. It indicated that both of the Medias exhibit derivative effect. The effect of the 1 is better than the 2 . The potassium mass of the two culture media accounts for $2.44 \%$ and $2.12 \%$ of the glass fiber, respectively. It may be attribute to the fact that the structure between the glass fibers is too tight and the force between the molecules is too strong. The actual degradation rate caused of the fibers is not particularly high, which needs further research.

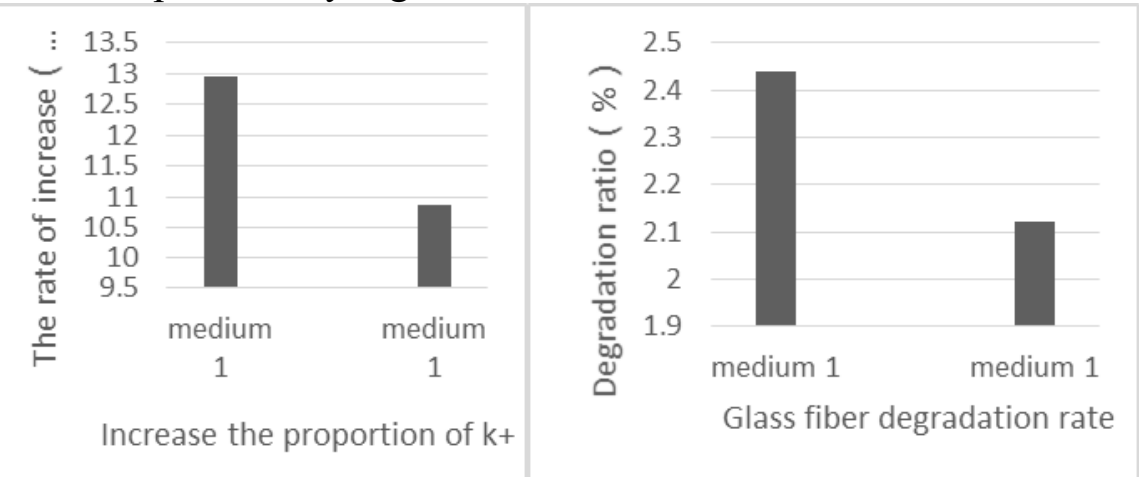

Figure 5. Comparison of two Medias

Treated glass fiber surface analysis.Through comparative observation of Figure 6, we found that the surface of the original (shown in Figure 6 (a)) is relatively smooth and clean. Whereas, after being degraded by the microorganism, the surface of the glass fiber (shown in Figure 6 (b)) turned to be rough. The existence of large amounts of ravines was ascribed to the formation of polysaccharides and organic acids during the growth procedure of Bacillus mucilaginosus. For the contact between polysaccharides and organic acids with the surface of the glass fiber, the glass fiber was eroded [14-16]. The coordinate bonds were generated by parts of the uronic acid and metal ions, thereby weakening the interaction force between oxygen and $\mathrm{K}^{+}$. Hence, the balance of the reaction was changed. Ultimately, the reaction was carried out towards the equilibrium of dissolution.

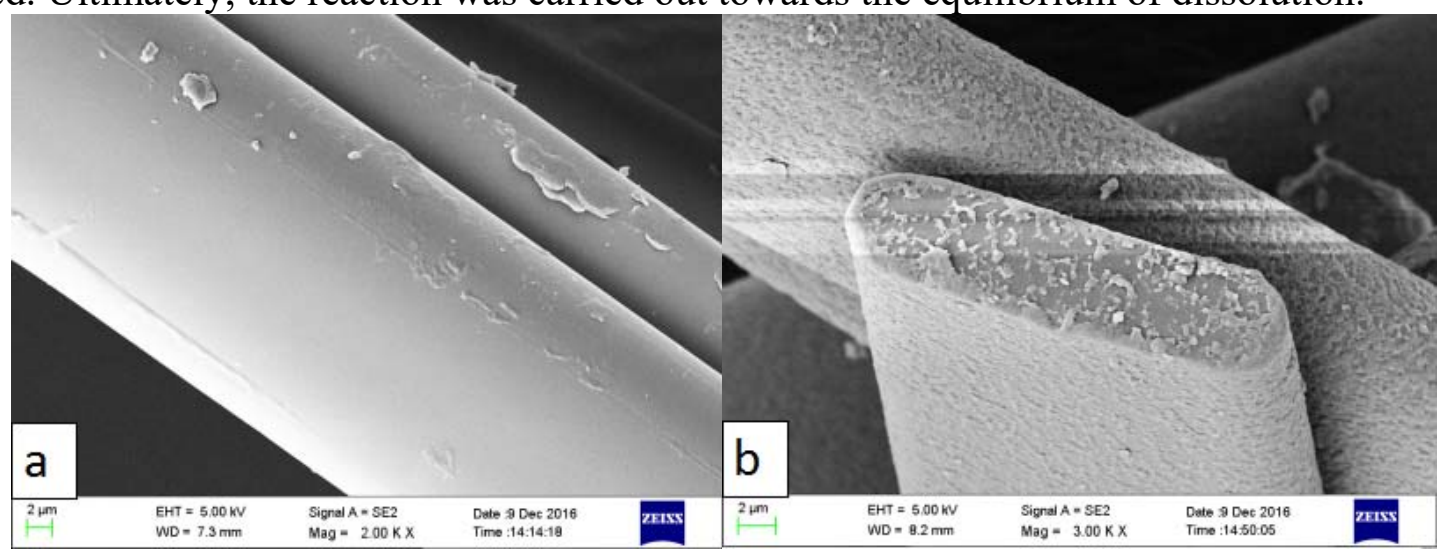

Figure 6. Scanning Electron Microscope of glass fiber surface: (a) Untreated glass fiber (b) Treated glass fiber

\section{Conclusion}

The XSC-6 strain, with the best degradation ability of glass fiber, was selected from the Changing district using the potassium shale mineral powder. It was identified as Bacillus mucilaginous by the sequence analysis of $16 \mathrm{~S}$ drank and morphological characteristic. The Fire Wire Photometer and scanning electronic microscope were used to measure the $\mathrm{K}^{+}$content and microstructure. The results indicated that the strain exhibited the feasibility in the degradation of glass fiber. This paper provides a certain theoretical basis for the biodegradation of glass fiber, whether it can be carried out on a large scale and application still needs further study. 


\section{References}

[1]. Gladysheva T V, Gladyshev N F, Dvoretskii S I. Phase composition of the carbonatization product of nanocrystalline $\mathrm{KO} 2$, deposited on a glass fiber matrix [J]. Inorganic Materials, 2016, 52(5):459-463.

[2]. Mukhammadiyeva G F, Karim ova L K, Beige N A, et al. Peculiarities of air pollution in the production of continuous glass fiber [J]. Gigiena I Sanitariia, 2016, 95(6):548.

[3]. Quantification and mapping of the impact of the recent air pollution abatement on limestone and window glass in Paris

[4]. Gaol Y Z. Optimization and application of liquid deep fermentation process of Bacillus mucilagiosus [D]. Qilu University of Technology, 2015.

[5]. Monika T, Hirayama N, Minami K, et al. GLASS COMPOSITION FOR GLASS FIBER, US20170226003 [P]. 2017.

[6]. Qin W, Mu Y G, Lu Li H et al. Screening and Breeding of a High Potassium Bioactive Bacillus Strain [J]. Shanxi Agricultural Science, 2015, 43(4):434-438.

[7]. Li S Study on the Change of Microorganism during the Cultivation of Microbial Fertilizers by DGGE [D]. Beijing University of Chemical Technology, 2012.

[8]. Wang X, Leaning L I, Pan G, et al. Compound of Bacillus mucilaginosus and Biochar and Its Effects on Tomato Yield and Quality [J]. Soils, 2016.

[9]. Qin W, Yao-Guy M U, Li-Hua L, et al. Screening and Breeding of a Bacillus mucilaginosus Strain with Strong High Ability of Potassium Releasing [J]. Journal of Shanxi Agricultural Sciences, 2015.

[10]. Yang M, Liang Y, Dou Y, et al. Characterisation of an extracellular polysaccharide produced by Bacillus mucilaginosus MY6-2 and its application in metal biosorption [J]. Chemistry \& Ecology, 2017(3):1-12.

[11]. Li B Zhao X, Wang Yan, et al. Research Progress of Industrial Fermentation of Bacillus Subtilize [J]. Journal of Agricultural Sciences, 2014, 35(1):68-72CHENYe,

[12]. Heterologously expressed carbonic anhydrase from Bacillus mucilaginosus promoting $\mathrm{CaCO}$ 3 formation by capturing atmospheric $\mathrm{CO} 2$

[13]. Yang M, Liang Y, Dou Y, et al. Characterisation of an extracellular polysaccharide produced by Bacillus mucilaginosus MY6-2 and its application in metal biosorption [J]. Chemistry \& Ecology, 2017(3):1-12.

[14]. Du Ye, Zhou Eyeing, Lian Bin. Extracellular secretions of Bacillus mucilaginosus and the potassium releasing effect of bacteria [J]. Earth Science Frontiers, 2008, 15(6):107-111.

[15]. Chain conformation and rheological behavior of exopolysaccharide from Bacillus mucilaginosus SM-01

[16]. Yu L, Cu X, Zhou J, et al. Chain conformation and rheological behavior of exopolysaccharide from Bacillus mucilaginosus, SM-01 [J]. Food Hydrocolloids, 2016, 65. 